\title{
Laser Acupuncture: 35 Years of Successful Application in Russia (Narrative Review)
}

\author{
Sergey Vladimirovich Moskvin ${ }^{1 *}$, Lev Georgievich Agasarov ${ }^{2 *}$ \\ ${ }^{1}$ O.K. Skobelkin State Scientific Center of Laser Medicine Under the Federal Medical Biological Agency, Moscow, Russia \\ ${ }^{2}$ National Medical Research Center of Rehabilitation and Resort Medicine of the Ministry of Health of Russia, Moscow, \\ Russia
}

\begin{abstract}
*Correspondence to
Sergey Vladimirovich Moskvin -

$\mathrm{PhD}$ of Technical Sciences, Leading

Researcher of The Federal StateFinanced Institution "O.K. Skobelkin State Scientific Centre of Laser Medicine under the Federal Medical Biological Agency" of Russia, Studencheskaya str., 40, Moscow, 121165, Russia; Email: 7652612@ mail.ru

Lev Georgievich Agasarov, Professor, Head of the Reflexotherapy and Clinical Psychology Department, Federal State Budgetary Institution "National Medical Research Center of Rehabilitation and Resort Medicine" of the Ministry of Health of Russia, Noviy Arbat, 32, 121099 , Moscow, Email: lev.agasarov@mail.ru

Published online October 3, 2020
\end{abstract}

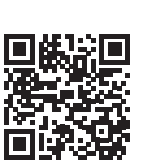

\begin{abstract}
Introduction: Laser acupuncture is one of the low-level laser therapy (LLLT) methods, replacing the traditional technique of Chinese needle acupuncture. This article describes the main principles and parameters of laser acupuncture based on the analysis of 35 years of successful experience in applying the method in Russia.

Methods: The search of the literature on laser acupuncture was made in the Russian Medical Library and the Russian State Library (1498 publications in Russian), and PubMed/Medline (117 publications in English). 96 studies on laser acupuncture techniques were selected and a narrative review was conducted.

Results: The optimal parameters of the technique were worked out by Russian specialists in the 1970s, and are perfectly confirmed by the wide practice of clinical application. The literature review showed that the most optimal parameters of laser acupuncture are wavelength - $635 \mathrm{~nm}$ (red spectrum), power - no more than 2-3 $\mathrm{mW}$, the diameter of special nozzle attachment - not more than 1-1.5 mm, and exposure - 20-40 s (for corporal points) or 5-10 s (for auricular points). The impact on acupuncture points (APs) is carried out consistently in accordance with the recipe (protocol), with no more than 10-12 daily procedures.

Conclusion: Laser acupuncture is a very effective and reproducible technique to treat patients with different diseases. Any specialist can apply this method because of its simplicity, but using the most effective parameters.

Keywords: Low-level laser therapy; Laser acupuncture; Low-intensity laser light; Laser parameters.
\end{abstract}

\section{Introduction}

Low-level laser therapy (LLLT) is a rapidly developing area of modern clinical medicine. Every year, the number of studies on the biomodulating effects of low-intensity laser illumination and the possibilities of laser therapy in various fields of medicine is growing. However, in publications published in English, unsuitable illumination parameters are often used, and these parameters, in our experience, are not suitable for influencing a living organism. Russian LLLT researchers still publish mostly in Russian, so that the treasure of their decades of experience is still mostly unknown to the international scientific community today. The purpose of this article is to present and examine the findings of Russian research in the field of laser acupuncture in particular.

Laser acupuncture is one of the two LLLT techniques for general (systemic) exposure in humans and animals. Percutaneous or intravenous laser blood illumination is the second technique. It is recommended to combine these methods with local laser illumination (in the projection of a nidus) to achieve the most effective LLLT. ${ }^{1}$

In the English-speaking environment, it is commonly assumed that F. M. W. $\mathrm{Plog}^{2}$ pioneered the use of laser light for acupuncture in 1973-74. ${ }^{3}$ Since 1979, Zhou has widely used this technique to treat surgical patients in China. ${ }^{4}$ In Russia (to be more precise, in the USSR), laser acupuncture began to be used alongside other LLLT methods in the period from 1970 to 1972 for treating patients with asthma, alopecia, hypertension, and some neurological diseases. ${ }^{5-7}$

The first Russian publications devoted to the study of the peculiarities of acupuncture point (AP) exposure to the laser light, the fundamentals and mechanisms of the biomodulating effect of LLLT, and the substantiation of optimal parameters of the technique appeared much earlier. ${ }^{89}$ The Russian founders of modern laser acupuncture methodology were Anischenko et $\mathrm{al}^{10}$ and Buylin. ${ }^{11}$ The wonderful Ukrainian school should not be 
left unmentioned. ${ }^{12,13}$

In the current study, we present the results of successful experience in the application of laser acupuncture in Russia, where hundreds of thousands of grateful patients of different ages (from 1 week to 100 years) have been effectively treated using this method. For 35 years, laser acupuncture in our country has been a standard in the treatment of a wide range of diseases, which is explained by high efficiency, and this, in turn, is due to correctly selected (justified) parameters (wavelength, power, time).

One of the main problems of modern LLLT is the difficulty in choosing the optimal parameters of the technique, and in our opinion, the exchange of experience will help specialists all over the world to get the right guidance for this purpose.

\section{Materials and Methods}

We conducted a narrative literature review on laser acupuncture. The main search was made in Russian libraries (the Russian Medical Library and the Russian State Library) - in Russian (1498 publications), and PubMed/Medline - in English (117 publications). 96 studies were selected for review according to the criteria for compliance with the requirements of Russian clinical recommendations on the optimal parameters of laser acupuncture techniques.

Understanding the methodology of laser acupuncture and substantiation of the optimal parameters of the technique (wavelength, spot size, power, modulation frequency range, etc) was formed several decades ago; therefore, references to fairly old works and monographs that combine numerous studies are used.

\section{Results and Discussion}

A total of 96 publications were analyzed, giving an opportunity to inform about the longest and most successful experience in applying the method.

Laser acupuncture is referred to as one of the reflexotherapy options in numerous thematic manuals and monographs. ${ }^{14,15}$ The essence of the technique consists in the activation of biologically active zones, also known as APs, by exposing them to low-intensity laser illumination. Microscopic light energies are required to activate APs. Therefore, the technique requires minimal laser power and exposure. Exceeding these values results in the suppression of the AP activity, and these points cease to "work."

An AP is an area of the maximum activity of the integument-viscera interaction system that is projected onto the skin. AP physiological characteristics are specifically related to changes in the functional state of the internal organs and neural connections associated with them in the corresponding parts of the brain.

The sequence of AP localization and stimulation (the recipe) is chosen according to the principles of Traditional Chinese Medicine (TCM). However, in laser acupuncture techniques, the "classical" number of points is often reduced to simplify the procedure. The reduction in the number of points is not due to objective facts (increase in efficiency), but due to poor training in TCM. Laser acupuncture is increasingly used not by specialists in the field of acupuncture, but by doctors of completely different specialties, and even ordinary people.

To activate the desired AP rather than neighboring one that has other properties, a very small area no more than $1-1.5 \mathrm{~mm}$ in diameter needs to be illuminated. Special acupuncture nozzles attachments (Figure 1) are designed to concentrate the laser beam. These are also used for contact techniques (applied in dermatology and cosmetology). ${ }^{16}$

In the mid-1970s, a number of Russian researchers showed that when acting directly on nervous tissue, LLLT causes numerous responses, including modulation of the intact motor nerve excitability, ${ }^{17}$ changes in the neural firing rate, ${ }^{18}$ activation of synaptic processes, increased rate of elementary reactions and reduced time for excitation transfer from presynaptic to postsynaptic structures, ${ }^{19}$ neuron membrane depolarization, pulsed response potency acceleration and enhancement of bioenergetic processes, ${ }^{20}$ accelerated axonal growth (the process of axial cylinder myelination), ${ }^{21}$ and acceleration of peripheral nerve regeneration, restoration of its functions and bioelectric activity in a denervated skeletal muscle..$^{22-25}$

These works formed the fundamental scientific basis to substantiate the techniques for stimulating the reflex zones and laser acupuncture. The technique was called "reflexotherapy", focusing on the relationship between AP and the reflex response of the nervous system. There is a separate medical specialty, namely "doctor-reflexologist", in Russia ${ }^{26}$; however, laser acupuncture can be carried out by other specialists, providing the medical service of "Laser puncture" (code: A17.01.002.03), ${ }^{27}$ guided by a rather wide range of indications and contraindications. ${ }^{28}$

Laser light is not only a very convenient alternative to traditional needles and the complicated manipulation techniques they require, but also a more efficient tool. The study by Denisova ${ }^{29}$ is of interest in this respect; the scholar directly compared the effectiveness of these three methods in patients suffering from gonarthrosis: classical

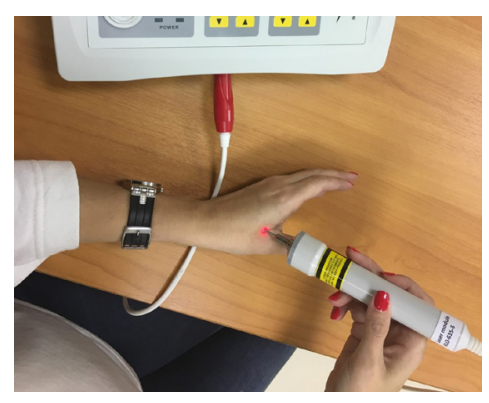

Figure 1. The Process of AP Laser Illumination. 
acupuncture, AP exposure to electromagnetic radiation of the extremely high frequency (EHF) range, and LLLT. It was shown that laser exposure to EHF radiation is most preferred, while using laser light for acupuncture is also more effective than using traditional needles (Figure 2$)^{30}$.

In comprehensive medical rehabilitation, the EHFpuncture technique is an alternative for children and hypersensitive patients as it is a non-invasive and painless technique with the ability to restore the functional balance of the meridian system as well as classical acupuncture is able to. In the comprehensive rehabilitation of patients with rheumatoid arthritis, it is preferable to conduct laser acupuncture for the purpose of pain relief. ${ }^{31}$ According to Avdey, ${ }^{32}$ in patients with osteochondrosis, the use of laser acupuncture is more preferable for a disease duration of up to 5 years, and EHF-puncture and needle acupuncture is more effective after 5 years.

It has been proven that APs are very sensitive to different physical (electromagnetic) fields. Systemic responses of the body, the direction of which depends on the energy parameters of the effect, are activated; that is, laser activation of TAs can have not only a tonic character, but also a tone-reducing character.

Features and advantages of laser acupuncture techniques:

- $\quad$ small exposed zone (diameter $\sim 1 \mathrm{~mm}$ )

- exceptional ease of use

- non-invasive, aseptic, comfortable procedure

- possibility of using the technique by doctors of all medical specialties

- accurate dosing of the exposure

- minimum time required for the procedure

- control over the reflex response direction

- nonspecific pattern of receptor structure

- ability to combine the technique with any type of treatment

- $\quad$ high effectiveness.

Laser exposure does not cause subjective sensations in patients if the correct parameters of the technique are used. The phylo- and ontogenetic structure of the physiological processes in the human body determines a wide range of vegetative reactions of the body to AP bioactivation through the response of the ANS and the CNS, which has been proven by numerous studies. ${ }^{11,33}$

The point effect of the minimum energy of laser light in the AP zone results in the normalization of homeostasis due to the space-time summation.

The choice of the wavelength $(635 \mathrm{~nm})$ is explained by the penetration of light energy into the tissue at the optimum distance, deep enough for the desired structures to fall into the illumination zone. This is confirmed by our 35 years of practical experience, ${ }^{33}$ based on which the basic exposure scheme (recipe) for the normalization of sympathetic and parasympathetic regulation, activation of microcirculation is designed (Figure 3$)^{33}$ :

- 1-3-5 days of the week: LI4 (Hegu), ST36 (Zusanli) -

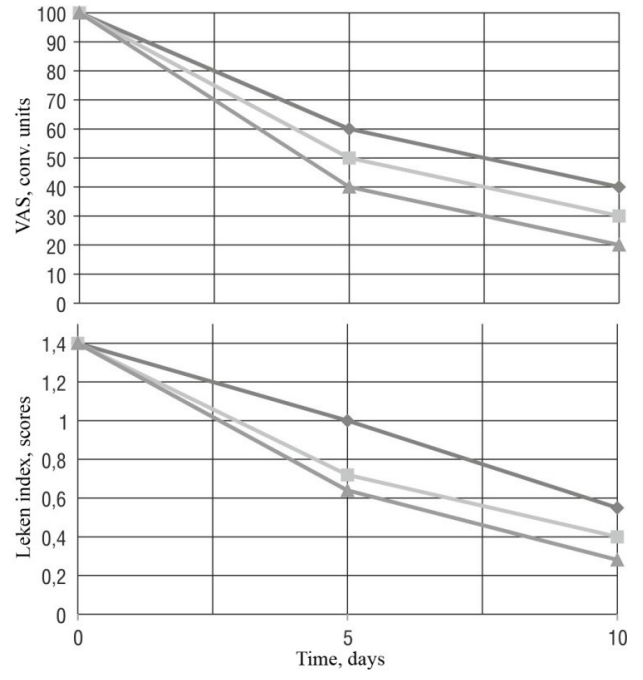

Figure 2. Dynamics of Pain Syndrome (According to the Visual Analogue Scale) and the Total Leken index in Patients With Gonarthrosis With Different Methods for AP stimulation. $\Delta$ needles, $\mathbf{E H F} \bullet$ LLLT.

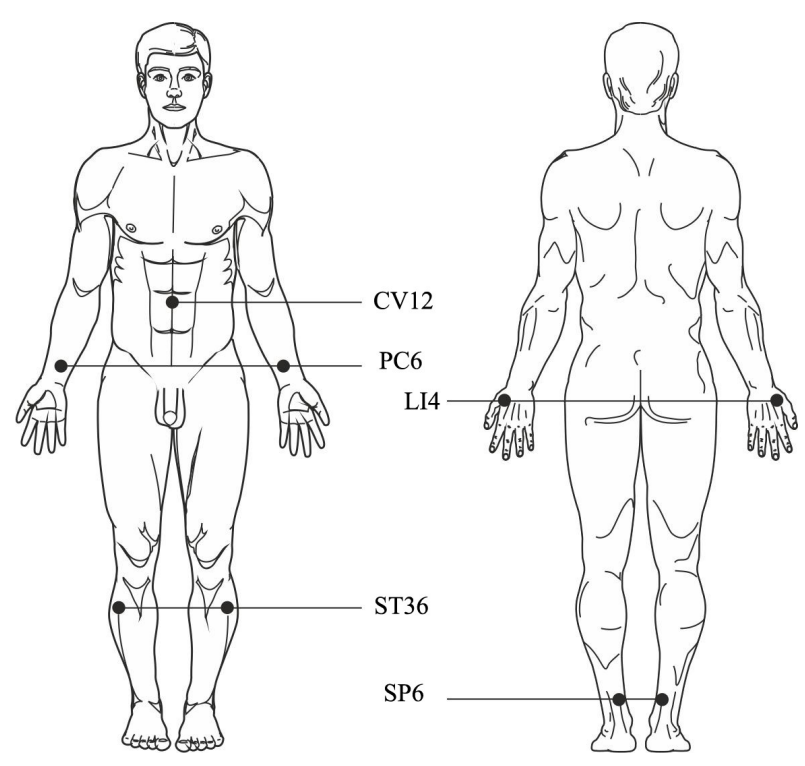

Figure 3. "Basic Recipe" (Protocol) for Laser Acupuncture.

symmetrically, CV12 (Zhongwan);

- on Tuesday, Thursday and Saturday: PC6 (Neiguan), SP6 (Sanyinjiao) - symmetrically, CV12 (Zhongwan).

- On Sunday, LLLT is not carried out. Additional (hourly) APs can be used:

- $\quad 2$ h - LR1 (Dadun)

- $4 \mathrm{~h}$ - LU8 (Jingqu)

- $6 \mathrm{~h}-\mathrm{LI} 1$ (Shangyang)

- 8 h-ST36 (Zusanli)

- $10 \mathrm{~h}-\mathrm{SP} 3$ (Taibai)

- $12 \mathrm{~h}-\mathrm{HT} 8$ (Shaofu)

- $14 \mathrm{~h}-\mathrm{SI} 5$ (Yanggu)

- 16 h-GV6 (Jizhong)

- 18 h-KI8 (Jiaoxin) 
- $20 \mathrm{~h}-$ PC8 (Laogong)

- $22 \mathrm{~h}$ - TE6 (Zhigou)

- $24 \mathrm{~h}-$ GB41 (Zulinqi).

The order of exposure: first APs of the head, then the auricle, corporeal and distal APs. The doctor should be well aware of the localization of points and immediately place the acupuncture attachment on the desired APs with little pressure. In addition to the rules known to reflexologists, it is advisable to take into account some general neurophysiological connections. ${ }^{34}$

Table 1 presents the most optimal parameters for laser acupuncture. When exposed to corporal points with continuous or modulated red light $(635 \mathrm{~nm})$, the power at the end of the acupuncture attachment is $2-3 \mathrm{~mW}$ (without modulation) and 1-1.5 mW (with modulation). ${ }^{11}$ When exposed to auricular points, the green spectrum $(525 \mathrm{~nm})$ is used, since such illumination is absorbed much more strongly and scattering is minimal, which ensures the selectivity of the exposure.

If the exposure is carried out in a modulated mode, the frequency is used from 1 to $10 \mathrm{~Hz}$ to achieve the stimulating effect, and $20-100 \mathrm{~Hz}$ for inhibition. ${ }^{35}$

Laser acupuncture is characterized by the inflexibility of the physical parameters of the technique: wavelength, power, and exposure time. Various aspects of laser acupuncture are discussed in detail in the review by Litscher and Opitz. ${ }^{36}$ Specifically, they cover the very important issue of optimizing the area of scattering over the surface and the laser light penetration depth depending on the wavelength. However, their work calls for some comments and clarifications. An interesting review is presented by Whittaker, ${ }^{3}$ who considered the prospects for the method and mechanisms for the implementation of the main effects.

The first task is to ensure the accuracy of the spatial characteristics of the technique. Laser emitting heads for devices of LASMIK series are intended to stimulate the corporal APs: KLO-635-5 (maximum power), or KLO-635-15 (reduced and controlled power) with an

Table 1. Parameters of Laser Acupuncture

\begin{tabular}{|c|c|c|}
\hline Parameter & Value & Note \\
\hline \multirow{2}{*}{$\begin{array}{l}\text { Wavelength, nm } \\
\text { (spectrum) }\end{array}$} & 525 (green) & On auricular AP \\
\hline & 635 (red) & On corporal AP \\
\hline Mode & $\begin{array}{c}\text { Continuous or } \\
\text { modulated }\end{array}$ & - \\
\hline $\mathrm{F}, \mathrm{Hz}$ & In the recipe & Only for a modulated mode \\
\hline \multirow{2}{*}{$\mathrm{P}^{*}, \mathrm{~mW}$} & $0.5-1$ & $525 \mathrm{~nm}$ \\
\hline & $2-3$ & $635 \mathrm{~nm}$ \\
\hline \multirow{2}{*}{ Time per $1 \mathrm{AP}, \mathrm{s}$} & $5-10$ & Onto auricular AP \\
\hline & $20-40$ & Onto corporal AP \\
\hline Number of APs & Up to 15 & - \\
\hline Number of procedures & $5-12$ & Daily \\
\hline
\end{tabular}

* At the output of acupuncture attachment.
A-3 acupuncture attachment (light guide diameter not exceeding $1 \mathrm{~mm}$ ). The APs are localized by doctors according to special atlases and guided by their own experience.

It is popularly believed that it is possible to determine the exact AP location by the minimum skin resistance with appropriate devices that are sold for this purpose. However, Kachan and Bogdanov, ${ }^{37}$ having examined the electrophysiological properties of APs, came to the conclusion that point localization by the amount of skin resistance to an electric current can be determined only very approximately since this indicator depends on the level of water-salt metabolism, blood circulation and microcirculation in the skin. Hyperemia and edema can also significantly change the skin electrical resistance, which, additionally, depends on the functional state of the nervous and endocrine systems (excited or depressed state of a person). Errors may also occur under the influence of external factors: season of the year and time of day, physical properties of the atmosphere, solar activity, nature of the contact, humidity, parameters of the probing signal, and so forth. Therefore, it is unacceptable to localize APs by this method.

The wavelength is the most important parameter of any LLLT technique. Previously almost all clinicians used to apply helium-neon laser light (633 nm laser wavelength, 2-6 $\mathrm{mW}$ power) for laser acupuncture. The work by Buylin, ${ }^{38}$ is an exception; the scholar used infrared (IR) laser diodes with a $1264 \mathrm{~nm}$ wavelength, which is close to the second harmonic of red light $(633 \mathrm{~nm} \times 2=1266$ $\mathrm{nm}$ ). The author relied on the "theory of singlet oxygen" in his choice mentioned in the first part of the book. It seems likely that this was also a verification of the option proposed by Romodanov et al, ${ }^{39}$ who paid attention to the identity of laser illumination and moxibustion, an ancient Chinese method of burning dried mugwort on particular points on the body, having one of the maxima of its luminous spectrum in this area $\approx 1300 \mathrm{~nm}$. However, since it is preferable to see the place of the illumination to obtain a guaranteed and reproducible result, infrared (that is, invisible) LLLT was abandoned.

To choose the wavelength is also important for the technique because of purely biophysical considerations, since it is necessary to take into account the substantial differences in the depth at which the APs are located and their proximity to each other. The accuracy of exposure localization is important for very closely spaced APs (auricular points). That is why LLLT is used in the green range $(525 \mathrm{~nm})$, as the absorption at this wavelength is significantly higher than in the red region of the spectrum. ${ }^{40}$ Accordingly, irradiation scattering is reduced, the illumination area is limited, which ensures the required selectivity (positioning and localization accuracy), and only the necessary points are exposed as required by the method, without significant impact on 
other APs located nearby.

For example, Branco and Naeser ${ }^{41}$ recommend to use a red laser $(633 \mathrm{~nm}, 15 \mathrm{~mW}$ ) for patients with carpal tunnel syndrome to stimulate APs nearby the skin surface, and pulsed infrared (905 nm, $9 \mathrm{~W}$ pulsed power) to illuminate deep-seated affected tissues and organs. There are publications in which other wavelength values were used to stimulate corporal APs: $405 \mathrm{~nm},{ }^{36} 658 \mathrm{~nm},{ }^{42} 670$ $\mathrm{nm},{ }^{43} 685 \mathrm{~nm},{ }^{36,44} 830 \mathrm{~nm},{ }^{45,46} 950 \mathrm{~nm},{ }^{47}$ and so on. But the parameters specified in Table 1 are most optimal.

Laser power is another important parameter. We emphasize again that power of no more than 2-3 $\mathrm{mW}$ should be used for laser acupuncture! It is not uncommon to find completely insane recommendations in the literature regarding the performance to be used.

For example, Kneebone ${ }^{48}$ recommends to relieve pain by illuminating APs with a "red laser" (no wavelength indicated) for 30-60 $\mathrm{s}$ at a power of 5-20 mW, for 10-20 $\mathrm{s}$ at $50-250 \mathrm{~mW}$ and for $5-10 \mathrm{~s}$ at $500 \mathrm{~mW}$ and more (ranging from 2 to 4 min per 1 session)! For reference, local exposure at $500 \mathrm{~mW}$ (it is frightful even to think about "greater" values) will result in a severe burn. Let us refer to one of the publications, as an example of what and how should not be done in any case when performing laser acupuncture, and laser therapy in general. ${ }^{49}$ All parameters are extremely far from the permissible ones.

Many years ago it was shown that exposure time for laser acupuncture (633-635 nm wavelength, 2-3 mW) should be limited to $30-40 \mathrm{~s}$, in contrast to classical acupuncture, where completely different temporal parameters (5-15 min) are applied. ${ }^{8}$ Currently, continuous LLLT (635 nm wavelength, 2-3 $\mathrm{mW}$ output power at an acupuncture nozzle to be controlled obligatorily) is most often used to illuminate corporal APs with an exposure time not exceeding 20-40 s per a point. ${ }^{11,33}$ Leontyuk et $\mathrm{al}^{50}$ pay attention to the age-related features of the response of some organs of the endocrine, immune and sympathoadrenal systems after laser acupuncture and strongly recommend to consider the patient's age when prescribing this procedure. This refers to the recipe adjustment.

Laser acupuncture is an integral part of LLLT; it has long and widely been used in practical healthcare in Russia and other countries. This is only a small list of relevant publications in the main areas of medicine:

- $\quad$ obstetrics and gynecology $y^{51-56}$;

- $\quad$ angiology ${ }^{57}$;

- $\quad$ andrology and urology $y^{58-61}$;

- $\quad$ veterinary medicine and agriculture ${ }^{62-67}$;

- $\quad$ gastroenterology $y^{68,69}$;

- dermatology ${ }^{70,71}$;

- $\quad$ musculoskeletal diseases ${ }^{31,72}$;

- $\quad$ infectious diseases ${ }^{73}$;

- $\quad$ cardiology $y^{74,75}$

- cosmetology ${ }^{16,76}$;

- $\quad$ neurology $y^{10,32,77-80}$;
- $\quad$ otorhinolaryngology $y^{81,82}$;

- ophthalmology ${ }^{83-86}$;

- $\quad$ pediatrics ${ }^{84,85,87,88}$;

- $\quad$ psychiatry $^{89-91}$;

- $\quad$ pulmonology $82,92-94-96 ;$

- $\quad$ sports medicine ${ }^{97}$;

- dentistry ${ }^{98-101}$;

- phthisiology (the care, treatment, and study of tuberculosis) ${ }^{102-104}$;

- $\quad$ surgery ${ }^{38,80}$; endocrinology. ${ }^{105-108}$

The optimal parameters of the technique were worked out by Russian specialists in the $70 \mathrm{~s}$ of the last century, and all these years the conclusions drawn are perfectly confirmed by the wide practice of clinical application. If you change the optimal values of the wavelength, power, and most importantly the exposure, then the APs either do not respond properly, for example, when the power decreases, or stop responding to any stimulus after some time at high power.

The size and format of the article do not allow a detailed examination of each study; there are a lot of them and most of them were carried out with a placebo when there was the contact of the special acupuncture nozzle and the laser was not turned on. In addition, over 35 years of mass use of the method, there were many opportunities and proposals for changing the parameters of the methodology that we presented above, and all of them did not receive recognition. This certainly confirms the correctness of our recommendations.

\section{Conclusion}

In summary, laser acupuncture has gained a reputation of a highly effective and reproducible technique for treating patients with the widest range of diseases; any specialists can apply this method because of its simplicity, but using the most effective parameters (wavelength, mode of operation, power, illuminated area and exposure time).

The literature analysis shows that it is most optimal to conduct 5-12 daily laser acupuncture procedures with a wavelength of $635 \mathrm{~nm}$ (red spectrum), power of no more than 2-3 mW, exposure of 20-40 s for corporal points and $5-10 \mathrm{~s}$ for auricular points. The impact on APs is carried out consistently in accordance with the recipe (protocol).

The effectiveness of laser acupuncture is beyond doubt, ${ }^{109-112}$ and it is necessary to make it as effective as possible with reproducible treatment results.

\section{Ethical Considerations}

Not applicable.

\section{Conflict of Interests}

The authors declare no conflict of interest.

\section{References}

1. Gerasimenko MY, Geynits AV, Moskvin SV, Astahkov PV, Babushkina GV, Gushchina NV, et al. Laser therapy in 
medical rehabilitation and prevention programs: clinical guidelines. Moscow; 2015. [Russian].

2. Plog FMW. Biophysical application of the laser beam. In: Koebner HK, ed. Lasers in Medicine. New York: John Wiley; 1980.

3. Whittaker P. Laser acupuncture: past, present, and future. Lasers Med Sci. 2004;19(2):69-80. doi: 10.1007/s10103004-0296-8.

4. Zhou YC. An advanced clinical trial with laser acupuncture anesthesia for minor operations in the oro-maxillofacial region. Lasers Surg Med. 1984;4(3):297-303. doi: 10.1002/ lsm.1900040311

5. Voronina NN. Changes in some functional parameters in patients with bronchial asthma under the influence of laser light. In: Proceedings of the Republican Conference "Some issues of biodynamics and bioenergy of the body in health and pathology, biostimulation with laser irradiation." Alma-Ata; 1971. [Russian].

6. Shchur VV, Makeeva NS, Belyaev VP, Starshinov GV. To the question of the results of treatment of arterial hypertension and some neurological diseases by monochromatic red light of helium-neon laser. In: Proceedings of the Republican Conference "Some issues of biodynamics and bioenergy of the body in health and pathology, biostimulation with laser irradiation." Alma-Ata; 1971. [Russian].

7. Gamaleya NF. Laser biomedical research in the USSR. In: Wolbarsht ML, ed. Laser Applications in Medicine and Biology. Vol 3. Boston: Springer; 1977.

8. Dzevitskaya MT. Changes in the information characteristics of the heart rate as a result of exposure by various methods of reflexotherapy to BAP. In: Means and methods of quantum electronics in medicine. Saratov: Publishing House of Saratov State University; 1976. [Russian].

9. Dzevitskaya MT, Akenshina GV. Electrical conductivity of the skin of the auricle, depending on the nature of the pathology and in the process of laser physiotherapy treatment. In: Means and methods of quantum electronics in medicine. Saratov: Publishing house of Saratov State University; 1976. [Russian].

10. Anischenko GYa, Polyanskaya ZM, Dallakyan IG. Laserpuncture in neuropathology. Moscow; 1991. [Russian].

11. Buylin VA. Laser reflexology. Moscow: Tekhnika; 2002. [Russian].

12. Samosyuk IZ, Lisenyuk VP, Loboda MV. Laser therapy and laser puncture in clinical and resort practice. Kiev: Zdorov'ya; 1997. [Russian].

13. Samosyuk IZ, Samosyuk NI, Fedorov SN, Zalesskiy VN. 50 years of laser medicine: horizons of laser puncture - a modern technology of reflexotherapy. Kiev: Vipol; 2012. [Russian].

14. Agasarov LG. Reflexotherapy for common diseases of the nervous system (general and applied aspects). Moscow: Arnebiya; 2017. [Russian].

15. Agasarov LG. Reflexology guide. Moscow: Arnebiya; 2001. [Russian].

16. Geynits AV, Moskvin SV. Laser therapy in cosmetology and dermatology. Moscow-Tver: Triada; 2010. [Russian].

17. Mynzhanova NSh. Changes in the physiological characteristics of the excitability of the intact motor nerve exposed to laser irradiation. In: Biological action of laser irradiation (experimental and clinical aspects). Alma-Ata; 1977. [Russian].

18. Uzdenskiy $\mathrm{AB}$. The reaction of the isolated neuron on focused laser irradiation of its parts. In: Means and methods of quantum electronics in medicine. Saratov: Publishing House of Saratov State University; 1976. [Russian].

19. Adzhimolaev TA, Shepelev VA, Kutateladze IO, Muzykanskiy EL. Effect of helium-neon laser irradiation on function of neuromuscular apparatus. In: Means and methods of quantum electronics in medicine. Saratov: Publishing House of Saratov State University; 1976. [Russian].

20. Adzhimolayev TA, Zubkova SM, Laprun IB. Structural and functional changes in nerve cells under laser irradiation. In: Means and methods of quantum electronics in medicine. Saratov: Publishing House of Saratov State University; 1976. [Russian].

21. Rakhishev AR. The action of laser light on the peripheral mechanisms of nerve regeneration. In: Means and methods of quantum electronics in medicine. Saratov: Publishing House of Saratov State University; 1976. [Russian].

22. Dosaev T.M. Morphometric assessment of the state of nerve cells during stimulation. In: Biological action of laser irradiation (experimental and clinical aspects). Alma-Ata; 1977. [Russian].

23. Sisabekov KYe. The change of myoneural synapses under the infl uence of monochromatic red polarized light. In: Biological effects of laser irradiation (experimental and clinical aspects). Alma-Ata; 1977. [Russian].

24. Toygambaeva AZ. The effect of laser irradiation on some indicators of nerve regeneration. In: Biological action of laser irradiation (experimental and clinical aspects). AlmaAta; 1977. [Russian].

25. Tsoy VP, Tsoy YuV. Electrostimulation of denervated skeletal muscle during laser irradiation. In: Biological action of laser irradiation (experimental and clinical aspects). Alma-Ata; 1977. [Russian].

26. Order of Ministry of Health of the Russian Federation No. $1183 \mathrm{n}$ of 20.12.2012. "On approval of the nomenclature of positions of medical workers and pharmaceutical workers". [Russian].

27. Order of Ministry of Health of the Russian Federation No. $804 \mathrm{n}$ of 13.10 .2017 . "On approval of the nomenclature of medical services". [Russian].

28. Order of Ministry of Health of the Russian Federation No. $266 n$ of 13.04.2007. "On approval of the recommended lists of medical indications and contraindications for the use of reflexotherapy in clinical practice". [Russian].

29. Denisova EV. The use of EHF and laser puncture in the treatment of patients with osteoarthritis of the knee joints. In: Bulletin of Lobachevsky State University of Nizhni Novgorod. Biology series. Issue 1 (7). Electromagnetic fields and irradiation in biology and medicine. Nizhniy Novgorod: UNN Publishing House; 2004. [Russian].

30. Moskvin SV, Khadartsev AA. EHF-laser therapy. MoscowTver: Triada; 2016. [Russian].

31. Polyakova AG. EHF and laser puncture in complex medical rehabilitation of patients with pathology of the joints and spine [dissertation]. Moscow; 2004. [Russian].

32. Avdey GM. Clinical and immunological relationships in patients with neurological manifestations of lumbar 
osteochondrosis in the application of certain methods of treatment [dissertation]. Grodno; 1997. [Russian].

33. Moskvin SV, Buylin VA. Optimization of laser exposure. Low-intensity laser therapy. Moscow: TOO "Firma “Tekhnika”; 2000. [Russian].

34. Skupchenko VV, Milyudin ES. Phasotonic homeostasis and healing. Samara: Samara State Medical University; 1994. [Russian].

35. Vogralik VG, Vogralik MV. Puncture reflexology: zhenchiu. Gorkiy: Volga-Vyatka Publishing house; 1988. [Russian].

36. Litscher G, Opitz G. Technical parameters for laser acupuncture to elicit peripheral and central effects: Stateof-the-art and short guidelines based on results from the Medical University of Graz, the German Academy of Acupuncture, and the scientific literature. Evid Based Complement Alternat Med. 2012;2012:697096. doi: 10.1155/2012/697096.

37. Kachan AT, Bogdanov NN. Electrophysiological features of acupuncture points. In: Ulashchik VS, Kobrik VA, editors. Optimization of exposure in physiotherapy. Minsk: Belarus; 1980. [Russian].

38. Buylin VA. Semiconductor lasers in treatment of postoperative intestinal paresis [dissertation]. Moscow; 1990. [Russian].

39. Romodanov AP, Bogdanov GB, Lyashchenko DS. Primary mechanisms of acupuncture and cauterization. Kiev: Vishcha Shkola; 1984. [Russian].

40. Moskvin SV, Achilov AA. Basics of laser therapy. MoscowTver: Triada; 2008. [Russian].

41. Branco K, Naeser MA. Carpal tunnel syndrome: Clinical outcome after low-level laser acupuncture, microamps transcutaneous electrical nerve stimulation, and other alternative therapies-an open protocol study. $J$ Altern Complement Med. 1999;5(1):5-26. doi: 10.1089/ acm.1999.5.5.

42. Litscher G. Laser acupuncture - innovative basic research: visual and laser-induced evoked potentials. Laser Ther. 2012;21(4):287-295. doi: 10.5978/islsm.12-OR-17.

43. Lorenzini L, Giuliani A, Capra R, Giardino L, Calza' L. Laser acupuncture using an ULLL device: effectiveness in rat models of acute and persistent pain. Paper present at: Conference WALT; 2010 Sep 22-25; Norway.

44. Litscher G, Schikora D. Cerebral vascular effects of non-invasive laserneedles measured by transorbital and transtemporal Doppler sonography. Lasers Med Sci, 2002;17(4):289-295

45. Ohshiro T, Calderhead RG. Low Level Laser Therapy: A Practical Introduction. Chichester. John Wiley \& Sons; 1988.

46. Wu JH, Chen HY, Chang YJ, Wu HC, Chang WD, Chu YJ, et al. Study of autonomic nervous activity of night shift workers treated with laser acupuncture. Photomed Laser Surg, 2009;27(2):273-9. doi: 10.1089/pho.2007.2235.

47. Read A, Beaty P, Corner J, Sommerville C. Reducing naltrexone-resistant hyperphagia using laser acupuncture to increase endogenous opiates. Brain Inj. 1996;10(12):9119. doi: 10.1080/026990596123882.

48. Kneebone WJ. Laser acupuncture as a pain relief modality. Practical Pain Management. 2008:8(4):64-8.

49. Weber M, Fussgänger-May T, Wolf T. "Needles of Light": A new therapeutic approach. Med Acupunct. 2007;19(3):141151. doi: 10.1089/acu.2007.0539.

50. Leontyuk LA, Vilegzhanina TA, Ryzhkovskaya EL. Agespecific features of the reaction of some organs of the endocrine, immune and sympathoadrenal systems to laser puncture. In: Proceedings of the school-seminar "Laser technology and laser medicine". Khabarovsk; 1989. [Russian].

51. Demina TN, Berko EM, Galalu SI, Berko AT. The use of laser acupuncture in the treatment of threatened miscarriage. In: Proceedings of the III International conference "Current issues of laser medicine and endoscopy". Moscow-Vidnoe; 1994. [Russian].

52. Zakharov IV. The value of vaginal laser puncture in the combined treatment of patients with tubal infertility [dissertation]. Volgograd; 2005. [Russian].

53. Zulkarneeva EM. Features of the course, rational management of pregnancy, childbirth in young primiparas, depending on the state of physical and sexual development [dissertation]. Ufa; 1997. [Russian].

54. Kulavskiy VA, Kryukov LA. Laser puncture in the treatment of inflammatory diseases of the genitals. Natural and nondrug factors in promotion of health. Ufa; 1989. pp.126-8. [Russian].

55. Sidnev DA. New non-drug technology of preparing the body for childbirth by laser puncture method. Bashkortostan Healthcare. 2000;4:44-45. [Russian].

56. Fedorova TA, Moskvin SV, Apolikhina IA. Laser therapy in obstetrics and gynecology. Moscow-Tver: Triada; 2009. [Russian].

57. Araslanova VM. Comprehensive treatment of patients with obliterating atherosclerosis of the vessels of the lower extremities using reflexotherapy methods [dissertation]. Moscow; 2005. [Russian].

58. Vaynberg ZS, Likhter MS, Portnoy YuV. On the prospects for the use of laser puncture in the treatment of urological diseases. In: Abstracts of the conference "Problems of metrological support of measurements of characteristics of random fields and signals generated by biological objects". Moscow: Atomizdat; 1979. [Russian].

59. Vozianov AF, Pasechnikov SP, Kovtunyak ON. The use of laser reflexotherapy in the complex treatment of patients with chronic prostatitis complicated by copulative dysfunction. In: Abstracts of the Republic scientific conference "Sex education, sexual health and the harmony of marriage and family relations." Kiev; 1990. [Russian].

60. Kovalenko VV, Kovtunyak ON. The use of local negative pressure and laser reflexotherapy in the treatment of sexual disorders in patients with chronic prostatitis. In: Abstracts of the Republic scientific conference "Sex education, sexual health and the harmony of marriage and family relations." Kiev; 1990, pp.117. [Russian].

61. Tereshin AT, Istoshin NG, Putilin VA, Mashnin VV. Balneo-, laser therapy, acu- and laser puncture in the correction of infertility in patients with chronic prostatitis. Journal of New Medical Technologies. 2009;16(1):74-7. [Russian].

62. Zubova TV. Correction of the reproductive function of cows using various types of hardware effects on biologically active points [dissertation]. Moscow; 2009. [Russian].

63. Kazeev GV. Bioenergy of animals and the development 
of methods for its correction if there is violation of the function of reproduction [dissertation]. Moscow; 2003. [Russian].

64. Skorykh LN. Methods and techniques for the rational use of the genetic potential of stud rams of domestic and imported breeding in commercial sheep breeding [dissertation]. Stavropol; 2013. [Russian].

65. Stikina EO. Improving the performance and activation of the rehabilitation processes of sports horses using lowintensity laser irradiation [dissertation]. Divovo; 1998. [Russian].

66. Talalaev SA. The effect of laser acupuncture on the growth, development and meat productivity of young sheep of North Caucasian meat-wool breed [dissertation]. Stavropol, 2008. [Russian].

67. Taradaynik NP. Improving the methods of correction of the reproductive function of cows and heifers [dissertation]. Dubrovitsy; 2009. [Russian]

68. Loseeva AV. The effect of laser therapy on the clinical condition and the level of biologically active substances in the blood cells of patients with gastric ulcer and duodenal ulcer [dissertation]. Kazan; 2009. [Russian].

69. Smorchkova OS. Combined use of laser puncture and lowintensity irradiation of extremely high frequency in patients with gastroesophageal reflux disease and ulcerative lesions of the gastrointestinal tract [dissertation]. Voronezh; 2010. [Russian].

70. Volkov VM. The effectiveness of the integrated use of selective phototherapy and laser puncture in patients with psoriasis using modern domestic devices [dissertation]. Moscow; 1990. [Russian].

71. Moskvin SV. Laser therapy in dermatology: vitiligo. Moscow: Tekhnika; 2003. [Russian].

72. Korotkov AL. The use of thermolaser puncture for diseases of internal organs and the musculoskeletal system [dissertation]. Tomsk; 1997. [Russian].

73. Khromtsova OM. Clinical and pathogenetic characteristics and assessment of the possibility of recovery of those who often suffer from acute respiratory infections [dissertation]. Ekaterinburg; 1998. [Russian].

74. Sapozhnikov MYu. Development and scientific substantiation of the method of laser reflexotherapy in the rehabilitation treatment of patients with angina of effort [dissertation]. Cheboksary; 2012. [Russian].

75. Sofronova EV. The effect of laser therapy on the quality of life and the level of biologically active substances in the blood cells of patients with angina of effort [dissertation]. Cheboksary; 2007. [Russian].

76. Füchtenbusch A. Laser application and acupuncture in cosmetics. Füchtenbusch publishing and education; 1998.

77. Vasilyev YuN. Neurophysiological and neurochemical mechanisms of acupuncture analgesia and its pharmacological modulation [dissertation]. St. Petersburg; 1992. [Russian].

78. Kubasova ES. Laser puncture of myofascial pain syndrome. Lasers and life. 1999;19(71):12. [Russian].

79. Kochetkov AV, Moskvin SV, Karneev AN. Laser therapy in neurology. Moscow-Tver: Triada; 2012. [Russian].

80. Tyshkevich TG. Multi-level stimulation in the early rehabilitation of neurosurgical patients [dissertation]. St. Petersburg; 2014. [Russian].
81. Nasedkin AN, Moskvin SV. Laser therapy in otorhinolaryngology. Moscow-Tver: Triada; 2011. [Russian].

82. Nikitin AV, Esaulenko IE, Shatalova OL. Application of laser puncture in patients with bronchial asthma with concomitant chronic rhinosinusitis. System Analysis and Management in Biomedical Systems. 2008;7(3):563-5. [Russian].

83. Ivanov AN. Acupuncture and manual therapy in the treatment of patients with partial atrophy of the optic nerve of inflammatory, vascular and traumatic genesis [dissertation]. Moscow; 2011. [Russian].

84. Kozodaev VO, Tregubova VN. Treatment of myopia in children by the method of laser puncture using "Mustang-024" device. Laser Medicine. 2002;6(4):48-9. [Russian].

85. Tsikova TD. Laserpuncture in the complex treatment of low degree myopia in school-age children. Ophthalmology Journal 1990;1:39-42. [Russian].

86. Avdeev RV. The effectiveness of laser reflex puncture and oftalamin in the complex treatment of patients with primary glaucoma with compensated intraocular pressure [dissertation]. Voronezh; 2004. [Russian].

87. Aleksandrov VV, Danilina TN. Laser puncture in the treatment of children with long-term effects of traumatic brain injury. In: Abstracts of the 1st Volga scientificpractical conference "Lasers in medicine and ecology". Moscow-Samara: Technika; 1998.

88. Moskvin SV, Nasedkin AN, Osin AYa, Khan MA. Laser therapy in pediatrics. Moscow: EKSMO; 2010. [Russian].

89. Nasedkin AA. The use of low-intensity laser irradiation in the complex treatment of adolescent patients with heroin addiction [dissertation]. Moscow; 2004. [Russian].

90. Nasedkin AA, Moskvin SV. Laser therapy of patients with heroin addiction. Tver: Triada; 2004. [Russian].

91. Popova IE. The effectiveness of laser acupuncture for the treatment of tobacco smoking in patients with chronic bronchitis. System analysis and management in biomedical systems, 2007;6(3):621-3. [Russian].

92. Boykov KA. Clinical and morphological assessment of the effectiveness of treatment of chronic bronchitis using laser acupuncture [dissertation]. Moscow; 2000. [Russian].

93. Borodina MA. Features of cardiorespiratory relationships in elderly patients with chronic obstructive pulmonary disease and their correction using combined physiotherapy [dissertation]: Moscow; 2011. [Russian].

94. Danilina TN. The use of laser puncture in the treatment of bronchial asthma [dissertation]: Samara; 2004. [Russian].

95. Semenova RI. The prevalence of nonspecific lung diseases and the course of chronic obstructive bronchitis in a large city in an unfavorable environmental situation [dissertation]. Leningrad; 1989. [Russian].

96. Sukhova EV. Medical and psychological rehabilitation of patients with chronic lung diseases [dissertation]. Samara; 2002. [Russian].

97. Samoylov NG. Regularities of age morphology of the neuromuscular apparatus with different modes of motor activity and under conditions of its activation [dissertation]. Kiev; 1989. [Russian].

98. Britova AA. Laser reflexology in the prevention and treatment of periodontal diseases [dissertation]. St. 
Petersburg; 1992. [Russian].

99. Karpunina AV. Treatment options for hyperesthesia of hard tooth tissues using laser and magnetic reflexotherapy [dissertation]. Kazan; 1997. [Russian].

100. Mikhailov RI, Terekhova NV, Zemskaya EA. Laser therapy and laser acupuncture in patients with chronic aphthous stomatitis. Dentistry. 1992;3-6:27-28. [Russian].

101. Moskvin SV, Amirkhanyan AN. Methods of combined and associated laser therapy in dentistry. Moscow-Tver: Triada; 2011. [Russian].

102. Kuyliyev EM. The effectiveness of laser therapy in the preoperative and postoperative periods in patients with pulmonary tuberculosis with concomitant chronic bronchitis [dissertation]. Moscow; 1992. [Russian].

103. Morozkina NS. Laser acupuncture in the complex treatment of patients with bone and joint tuberculosis. In: Actual problems of extrapulmonary tuberculosis. Minsk; 1995. [Russian].

104. Putilina LP. Treatment of pulmonary tuberculosis combined with bronchial asthma using laser irradiation in complex therapy [dissertation]. Moscow; 1993. [Russian].

105. Dubinina II. Biochemical aspects of polyendocrinopathy: Epidemiology, clinical picture, diagnostics, treatment [dissertation]. Ryazan; 1996. [Russian].
106. Zubkova ST. Features of disorder of regional hemodynamics, oxygen supply of tissues and ways of their correction in patients with diabetic angiopathies of the lower extremities [dissertation]. Kiev; 1989. [Russian].

107. Luk'yanyuk EV. Clinical and physiological rationale for the use of laser puncture with distal diabetic neuropathy [dissertation]. Moscow; 1992. [Russian].

108. Naumova MI. The role of laser therapy in the rehabilitation of patients with diabetes [dissertation]. Odessa; 1997. [Russian].

109. Baxter GD, Bleakley C, McDonough S. Clinical effectiveness of laser acupuncture: a systematic review. J Acupunct Meridian Stud. 2008;1(2):65-82. doi: 10.1016/ S2005-2901(09)60026-1.

110. Kisselev SB, Moskvin SV. The use of laser therapy for patients with fibromyalgia: a critical literary review. J Lasers Med Sci. 2019;10(1):12-20. doi: 10.15171/jlms.2019.02.

111. Moskvin SV. Low-Level Laser Therapy in Russia: History, Science and Practice. J Lasers Med Sci. 2017;8(2):56-65. doi: 10.15171/jlms.2017.11.

112. Moskvin SV. Only lasers can be used for low level laser therapy. BioMedicine. 2017;7(4):4-11. doi: 10.1051/ bmdcn/2017070422. 